\title{
Dinámica de la población de Cosmopolites sordidus (Germar) (Insecta, Coleoptera, Curculionidae) en el cultivo del plátano en Ecuador
}

\author{
Armendáriz, Ignacio ${ }^{\mathrm{a}}$ Landázuri, Pablo $^{\mathrm{b}}$ - Taco, Marco $^{\mathrm{b}}$ - Ulloa, Santiago ${ }^{\mathrm{c}}$ \\ a Investigador PROMETEO, Universidad de las Fuerzas Armadas, ESPE. IASA 1 \\ 'Universidad de las Fuerzas Armadas, ESPE. IASA 1 \\ c Universidad de las Fuerzas Armadas, ESPE. IASA 2

\section{RESUMEN}

Durante el año 2014 se realizó una captura masiva de 5490 adultos del picudo del plátano (Cosmopolites sordidus) mediante trampeo con feromonas, con una media de 1,92 adultos· trampa-día durante 46 sema-nas. El ensayo, realizado en una parcela de plátano Barraganete en la localidad de El Carmen, Manabí, con seis años de antigüedad, manifiesta una presencia y actividad continua del insecto, correlacionada positiva-mente con la temperatura media y negativamente con la precipitación. Se exponen datos sobre la biología del picudo del plátano, principal plaga de esta musácea en todos los países donde es cultivada, de sus daños en el cultivo y de por qué pasa desapercibida a los agricul-tores. Se discuten las medidas de control posibles y las más asequibles para los productores.

Palabras clave: Captura masiva, control, feromonas, trampeo.

\footnotetext{
* Correspondencia a: Universidad de las Fuerzas Armadas ESPE, Av. General Rumiñahui s/n. P.O.Box 171-5-231B. Sangolquí. Ecuador. Correo
} de contacto: i.armendariz2009@gmail.com 